\title{
La sociología de la emoción y la emoción en la sociología
}

\author{
Eduardo Bericat Alastuey \\ Universidad de Málaga. Departamento de Sociología \\ Campus El Ejido, s/n. 29071 Málaga. Spain \\ ebericat@ucm.es
}

\section{Resumen}

En este artículo se presenta una síntesis de las aportaciones teóricas de tres pioneros de la sociología de la emociones: Thomas J. Scheff, Arlie R. Hochschild y Theodore D. Kemper. El profesor Scheff ha desarrollado un prolongado, amplio y riguroso programa de investigación empírica y teórica sobre la vergüenza y el orgullo, a las que considera las emociones sociales por antonomasia. La profesora Hochschild, frente a lo que constituye práctica habitual de la sociología, incorpora las emociones como una vía de acceso clave para el conocimiento de cualquier fenómeno o situación social. El profesor Kemper, a la inversa, muestra la validez y necesidad de la perspectiva sociológica para comprender las emociones, cuyo origen y fundamento deriva, en la mayor parte de los casos, de un determinado tipo de relación social.

Teorías sociológicas de la emoción, explícitamente concebidas como tales, no pueden encontrarse en la tradición sociológica antes de la década de los ochenta del presente siglo. La sociología, hasta ahora inmersa en la principal corriente cultural de la modernidad, caracterizada por un racionalismo, un cognitivismo y un positivismo a ultranza, tan sólo había incorporado tratamientos residuales o circunstanciales de la emoción. Ahora bien, resulta inconcebible un actor social cuyo universo simbólico esté exclusivamente compuesto de ideas o cogniciones. En este universo podemos encontrar también valores. Y en este universo también encontramos, sin duda, emociones. Emociones que son reflejo, condición y substrato último de toda reflexividad humana y social. Tanto la descripción como la explicación y comprensión sociológica de la realidad será incompleta, por tanto falsa, si no se incorpora al actor sentiente en los juegos humanos de interactividad e intercomunicación.

Palabras clave: sociología, teoría sociológica, emociones, sentimientos.

Abstract. The sociology of emotion and the emotion of sociology

This article presents a synthesis of the theoretical contributions of three pioneers in the field of Sociology of Emotions: Thomas J. Scheff, Arlie R. Hochschild and Theodore D. Kemper. Professor Scheff has developed a lengthy, extensive and rigorous empirical and theoretical investigation programme on the emotions of shame and pride, which he considers to be social emotions par excellence. Professor Hochschild, contrary to the habitual practice in sociology, incorporates emotions as a key means of access to comprehension of any phenomenon or social situation. Professor Kemper, on the other hand, demonstrates the validity and necessity of the sociological perspective in order to understand 
emotions, in most cases originating in and fundamentally derived from a certain type of social relationship.

Before the 1980's, sociological theories on emotions, explicitly conceived as such, were not present in sociological tradition. Immersed in the main cultural current of modernity, characterised by a fervent rationalism, cognitivism and positivism, until now Sociology had only incorporated residual or incidental treatment of emotions. However, a social actor whose symbolic universe is exclusively made up of ideas or perceptions is inconceivable. The universe also includes value, and, without a doubt, this universe includes emotions. These emotions are a reflection, a condition and the final substratum of all human and social reflexivity. The description, explanation and sociological understanding of reality will be incomplete, and therefore false, if the sentient actor in the human play of interaction and intercommunication is not incorporated.

Key words: sociology, sociologycal theory, emotions, feelings.

\section{Sumario}

1. Introducción

2. Theodore D. Kemper: poder y estatus en las relaciones sociales
3. Arlie R. Hochschild: normas sociales y estructura social 4. Thomas J. Scheff: vínculos sociales seguros e inseguros 5. Bibliografía

\section{Introducción}

La sociología del conocimiento, aplicada esta vez a la propia disciplina sociológica, deberá enfrentarse muy pronto con la tarea de explicar un enigmático e imperdonable olvido. Sólo ahora, sólo desde nuestro horizonte posmoderno, ahora que el velo de la modernidad empieza a rasgarse y el sistema muestra ya algunas de sus más queridas y sagradas coherencias, podemos preguntarnos cómo y por qué la sociología, ciencia del estudio de las lógicas de acción social y de las estructuras sociales, ha prescindido durante casi doscientos años de una dimensión humana tan íntimamente vinculada a la sociabilidad como la constituida por los afectos, las pasiones, los sentimientos o las emociones. La "construcción social de la realidad», aplicada en algunos casos repetida, típica y tópicamente a los fenómenos más peregrinos, insustanciales e irrelevantes, ha prestado escasa consideración a la realidad emocional de los seres sociales concretos y a la realidad emocional de las sociedades. La postulada «imaginación sociológica» tampoco ha osado traspasar el umbral afectivo, ni siquiera cuando la participación de las emociones en la acción y en la estructura social resulta evidente por sí misma. Ritos, carisma, legitimidad, creencias, valores, relaciones interpersonales, conciencia de clase, violencia, sentimientos nacionales, religión, revolución, desviación social, privación relativa, propaganda, comunicación, etc., etc., parecen difíciles de entender y explicar sin una consideración sociológica de las emo- 
ciones. Pero ya sabemos que las evidencias son engañosas. Sabemos desde hace tiempo que toda conciencia, incluso la sociológica, está constreñida por el tabú.

Gran parte de los maestros de la sociología, A. Comte, V. Pareto, E. Durkheim o M. Weber, ubicados intelectualmente en el paso de la sociedad tradicional a la sociedad moderna, hubieron de tratar los fenómenos afectivos, por lo que las emociones no están totalmente ausentes en sus trabajos. Sin embargo, como correspondía a la nueva época, estas emociones ocupaban un lugar marginal y, lo que es más sintomático, residual en el conjunto de su obra. Podría decirse que lucharon contra las emociones sin todavía ser capaces de eliminarlas. Sin embargo, cuando la modernidad se impuso en todos los órdenes de la vida, la impronta positivista barrió del pensamiento sociológico cualquier referencia emocional. En los casos más ambiciosos de teoría social, como en Talcott Parsons, se hubo de recurrir a términos extraños, como el de "catexis», para que la referencia emocional adoptara la categoría de un concepto científico. Incluso en estos casos, el tratamiento de la emoción en la sociología ha sido siempre residual, genérico e irrelevante.

Los sociólogos clásicos, como decimos, no dejaron de tener en cuenta las emociones en sus teorías, pero, dado el estatuto marginal que les otorgaron, su trabajo no sirvió al desarrollo de una explícita sociología de las emociones. Más bien ocurrió todo lo contrario. Max Weber puede considerarse un buen caso ilustrativo del tratamiento residual de las emociones, por un lado, así como del uso de emociones en la propia estructura de sus teorías y conceptos más fundamentales. El carácter residual es patente en la escasa atención que prestó en su obra a la "acción afectiva", así como en su propensión a identificar este tipo de acción con la conducta pasional, separando de este modo razón y sentimiento (Weber, 1979). Por otro lado, algunas de sus tesis no se sostienen sin tener en cuenta el eslabón emocional. El argumento clave de la ética protestante y el espiritu del capitalismo se estructura en un juego causal que comienza en el análisis ideológico de una religión, sigue con los efectos emocionales que esta ideología provoca en sus adeptos, básicamente cruel humillación, y termina con la modificación de pautas conductuales claves para el desarrollo del capitalismo, con el conocido efecto paradójico de adorar a Dios en el verbo, mientras se adora al becerro de oro en la práctica. Su tesis incluye con explicitud y claridad el componente emocional en el análisis sociológico (Weber, 1998), si bien este hecho ha tenido escaso eco en la sociología posterior.

E. Durkheim también tiene en cuenta el componente afectivo en su estudio del suicidio, en las respuestas colectivas a fenómenos de desviación social, o en las prácticas rituales. Una sociología del ritual y de la sacralidad que sólo puede entenderse cabalmente atendiendo a los vínculos afectivos que constituyen la esencia de lo social. En Durkheim conviven las ideas acerca de la naturaleza fundamentalmente afectiva del orden social (objeto), con las ideas que prevalecieron en la sociología posterior acerca de la necesidad de tratar los fenómenos sociales en tanto cosas (método). La riqueza de los análi- 
sis sociológicos de G. Simmel tampoco podían excluir totalmente la dimensión emocional del ser humano, como así mismo sucede en la obra de A. Comte, V. Pareto, Ch. H. Cooley, T. Parsons, G. C. Homans, R. Collins, N. Luhmann, E. Goffman y otros muchos. Sin embargo, no existe en ninguno de ellos ni un reconocimiento explícito de las emociones, ni unos conceptos emocionales que constituyan elementos clave de sus modelos. En estos sociólogos, por regla general, como señala acertadamente el profesor Scheff, no existen otros conceptos de emoción que los tomados en préstamo del lenguaje común, por tanto meros términos del lenguaje, pero en ningún caso conceptos que adquieren su sentido científico en el marco de una teoría.

Existen también obras sociológicas que incorporan en mayor medida o tratan directamente, incluso a veces sin nombrarlo, el mundo social de los sentimientos. Una referencia clave, en este sentido, es la obra de Norbert Elias El proceso de la civilización, donde nos narra procesos psico y sociogenéticos asociados al autocontrol de los impulsos emocionales y a modificaciones de la estructura emotiva de las sociedades en la modernidad. Gran parte de los análisis de Goffman, como se comenta más adelante, muestran las conductas externas de los encuentros sociales desde la perspectiva del reconocimiento o negación del estatus de los participantes en la interacción social, proceso directamente asociado a los sentimientos de deferencia o respeto en unos casos, y de turbación o vergüenza en otros. Richard Sennett y Jonathan Cobb, en The Hidden Injuries of Class, retratan el contenido emocional de los trabajadores de cuello azul de Boston, mostrando las heridas ocultas de la dignidad de hombres que ocupan posiciones sociales inferiores en una sociedad meritocrática que proclama la identidad entre capacidad y posición social. Tamotsu Shibutani, en su teoría sociológica del rumor, publicada bajo el título Improvised News, no deja de señalar, en la variada y rica colección de casos que aporta, el contexto o clima emocional del que suelen surgir y nutrirse los rumores. Willard Gaylin, en The Rage Within. Anger in Modern Life, estudia la naturaleza, las funciones y los contextos sociales en los que emerge la rabia, una rabia contenida, común, no explosiva, en las sociedades contemporáneas. Frank Furedi, en Culture of Fear, se pregunta acerca de las razones sociales del miedo, de la sensación de riesgo e incertidumbre respecto del mundo y de la sensación de desconfianza frente a los otros que cunde en la posmodernidad. La lista de estudios e investigaciones citadas podría fácilmente ampliarse (Hirschman, 1999; Dupuy, 1999; Giner, 1998), pero estos ejemplos bastan para dejar constancia de la existencia y el avance de una sociología de las emociones.

Teorías sociológicas de la emoción, explícitamente concebidas en tanto tales, no pueden encontrarse en la tradición sociológica antes de la década de los ochenta del presente siglo. En concreto, considerando las primeras publicaciones relevantes como punto de referencia, el nacimiento de la sociología de la emoción se remonta al año 1975, con la aparición en la sociología norteamericana de algunas obras pioneras. En 1975 Arlie Russell Hochschild publica, en un capítulo de libro, The Sociology of Feelings and Emotions; Tho- 
mas J. Scheff organiza en San Francisco la primera sesión sobre sociología de las emociones durante el Congreso de la American Sociological Association, y Randall Collins reflexiona sobre las relaciones entre ritual, poder y energía emocional en Conflict Sociology. Theodore D. Kemper publica A Social Inte raccional Theory of Emotions en 1978; Thomas J. Scheff, Catharsis in Healing, Ritual and Drama en 1979, y David R. Heise, Understanding events. Affect and the construction of social action en ese mismo año. También aparecen entonces los primeros artículos sobre sociología de la emoción en las revistas sociológicas de mayor prestigio (Kemper, 1990: 3-4).

Pese a sus veinticinco años de existencia, la sociología de la emoción sigue siendo una subdisciplina desconocida en muchos ámbitos académicos y comunidades científicas. Si bien ya cuenta en su haber con algunos importantes logros, su mérito principal estriba en que abre un importante horizonte de estudio social, necesario también, en mi opinión, para el desarrollo de metateorías sociológicas que subsanen el sesgo racionalista que afecta a casi todas ellas. En este artículo no se pretende hacer un resumen de los logros obtenidos, un estado de la cuestión o una consideración crítica de los mismos. Tan sólo se quiere presentar la obra de tres importantes pioneros en este campo: Thomas J. Scheff, Theodore K. Kemper y Arlie R. Hochschild.

En el contenido del artículo no se encontrarán apenas referencias a los intensos e interesantes debates metateóricos presentes en esta subdisciplina. Se ha optado, al contrario, por exponer las tres teorías siguiendo lo más cerca posible el espíritu y la letra de cada autor, sintetizando en un modelo formal de conceptos su núcleo teórico. Es obligado señalar, desde ahora, que las síntesis aquí realizadas no reflejan en absoluto la riqueza de matices presente en la obra de estos autores, algo que considero una traición al sentido tratándose del sutil mundo de los afectos. Aquéllos interesados por otras revisiones de la sociología de la emoción, ya publicadas, que incluyen los debates metateóricos aquí omitidos, pueden recurrir entre otros a los siguientes artículos: Shott (1979), Gordon (1981), Kemper (1981), Torregrosa (1982), Sheff (1983), Gordon (1985), Kemper (1987), Thoits (1989) y Kemper (1990a). Por estrictas razones de espacio, tampoco se han podido incluir otras teorías sociológicas de la emoción, entre las que cabe destacar la denominada Affect Control Theory, desarrollada inicialmente por otro pionero de la sociología de la emoción, David R. Heise ${ }^{1}$.

Los tres autores seleccionados sirven al tiempo para poner de relieve lo que a mi entender constituyen las tres líneas de trabajo que la sociología tiene ante sí, al considerar como uno de sus objetos de estudio la realidad emocional de los seres y las estructuras sociales. Estos tres campos son: la sociología «de» la emoción, la sociología «con» emociones, y la emoción «en» la sociología.

1. Esta teoría constituye un esfuerzo sistemático por incluir el componente afectivo en los modelos sociológicos del interaccionismo simbólico, modelos que desde su origen, en G. H. Mead, prescindieron de las emociones. Ver: Heise (1979), Smith-Lovin y Heise (1988) y MacKinnon (1994). 
En sentido estricto, la sociología «de» la emoción tiene como fin el estudio de las emociones haciendo uso del aparato conceptual y teórico de la sociología. Se trata de una sociología aplicada a la amplísima variedad de afectos, emociones, sentimientos o pasiones presentes en la realidad social. La fundamentación capital para este campo de estudio se encuentra en el hecho, señalado adecuadamente por la teoría interrelacional de Kemper, de que la mayor parte de las emociones humanas se nutren y tienen sentido en el marco de nuestras relaciones sociales. Esto es, la naturaleza de las emociones está condicionada por la naturaleza de la situación social en la que los hombres sienten. Son expresión, en el cuerpo de los individuos, del riquísimo abanico de formas de relación social. Soledad, envidia, odio, miedo, vergüenza, orgullo, resentimiento, venganza, nostalgia, tristeza, satisfacción, alegría, rabia, frustración y otro sinfín de emociones corresponden a situaciones sociales específicas. Éste es el objeto propio de la sociología de la emoción, estudiar las relaciones entre la dimensión social y la dimensión emocional del ser humano. Y ésta es precisamente la gran aportación de Kemper, más allá de sus errores o de sus imprecisiones. El autor, en concreto, relaciona dos conceptos clave de la sociología, el estatus y el poder, con cuatro emociones negativas (depresión, vergüenza, culpa y miedo), dando lugar así a una explicación sociológica de las mismas. Sin atender a la perspectiva relacional, clave de la perspectiva sociológica, no pueden entenderse la mayor parte de las emociones humanas. De este modo, la sociología abre y legitima un horizonte de estudio.

Pero la sociología no sólo ha de preocuparse de desentrañar la sociabilidad de las distintas emociones y sentimientos humanos, sino que debe incluir las emociones como un elemento más a tener en cuenta en los estudios correspondientes a todas y cada una de sus disciplinas. La sociología, según hemos dicho, ha estado realizando sus estudios sin considerar en absoluto, o sólo marginalmente, el contenido emocional de los fenómenos sociales que investigaba. En este sentido, la sociología «con» emociones representa la voluntad de incorporar el componente emotivo a nuestros estudios, del mismo modo que Weber, por ejemplo, lo incluyó a la hora de elaborar la tesis anteriormente comentada. Sin un matizado análisis emocional apenas pueden entenderse fenómenos como el patriotismo, el nacionalismo o, en general, la identidad colectiva. Habitualmente se estudian con precisión las ideologías nacionalistas, pero basta con una pregunta de un cuestionario de encuesta para determinar el «sentimiento nacional». Arlie R. Hochschild, en este sentido, nos muestra una vía de cómo la incorporación de las emociones en el estudio sociológico puede contribuir decididamente al descubrimiento de nuevos fenómenos sociales, así como a la precisa definición de su naturaleza. Sennet estudió la viviencia emocional de miembros ubicados en determinadas posiciones de la estructura de clases y con ello contribuyó también al entendimiento de esa misma estructura de clases. Collins ha estudiado el uso de las emociones en la dinámica de poder, y con ello contribuye al entendimiento del poder. En el peor de los casos, dado que en todo fenómeno 
social están implicados individual o colectivamente sujetos sentientes, el estudio de sus emociones proporcionará al sociólogo datos añadidos. En el mejor de los casos, esta inclusión le puede abrir la puerta a nuevas perspectivas, nuevas visiones de la realidad social que hubieran pasado desapercibidas de no atender a la estructura y a los procesos emocionales implicados en un determinado fenómeno. Hochschild también nos muestra, fundamentalmente, que las emociones no son un absoluto biológico, sino que están condicionadas por las normas sociales, y que participan de la reflexividad característica de todo fenómeno social.

En último término, a la sociología le queda la tarea de incorporar la emoción a su núcleo metateórico ${ }^{2}$ fundamental. Seguir prescindiendo de las emociones no constituye sólo un lamentable olvido, constituye un verdadero suicidio, una renuncia deliberada a la legítima aspiración por lograr explicaciones completas de la realidad y de los procesos sociales. Thomas J. Scheff es sin duda el autor que más profunda y rigurosamente aborda el estudio de las emociones desde una perspectiva metateórica esencial a la sociología. Se trata en este caso de un esfuerzo por incoporar la emoción «en» la sociología, esfuerzo que se sustenta sobre la comprensión social de los sentimientos de vergüenza y orgullo. Para Scheff estos sentimientos son expresión directa del vínculo social y definen la naturaleza de este vínculo. Más allá de los vínculos instrumentales que puedan unirnos a las personas, nuestros vínculos propiamente sociales se definen y alimentan por los procesos emotivos de la vergüenza y el orgullo. Una interacción social no susceptible de provocarnos vergüenza u orgullo no constituye un vínculo social en sentido estricto. De ahí que el estudio de estos sentimientos sean esenciales, tanto en el estudio del orden como del conflicto. La sociología «de» las emociones, así como la sociología "con» emociones, contribuyen al desarrollo de esta línea de trabajo capital iniciada por Thomas Scheff, trabajo que pone de nuevo sobre la mesa la pregunta acerca de qué es un vínculo social, pregunta clave para el desarrollo de una nueva sociología clara y distintamente diferenciada, tanto de los paradigmas económicos como de los psicológicos.

\section{Theodore D. Kemper: poder y estatus en las relaciones sociales}

La teoría sociológica de las emociones de Theodore D. Kemper se sustenta sobre dos presupuestos básicos. El primero pone de relieve el hecho de que «la inmensa mayoría de los tipos de emociones humanas derivan de los resultados reales, anticipados, imaginados o recordados producto de la interacción relacional» (Kemper, 78: 32). El segundo, un corolario del primero, sostiene que para entender los tipos de emociones, así como su génesis, será nece-

2. Para una precisión de los conceptos de metateoría, teoría y empiria, tal y como son utilizados en el texto, ver: «El estatuto del método en la investigación social», en Bericat, 1988, p. 91-102. 
sario contar previamente con un modelo que sistematice el juego, la esencia y las posibles consecuencias derivadas de las relaciones sociales. Pese a que el autor afirma sin ningún género de duda la naturaleza biológica de las emociones, remite a la situación social en la que se inscribe el sujeto para explicar su desencadenamiento interior. Esto es, existe un vínculo necesario entre subjetividad afectiva y situación social objetiva, lo que en último término justifica el proyecto de aplicar la perspectiva sociológica al estudio de las emociones $^{3}$. Si la mayoría de las emociones humanas se nutren en el contexto de las relaciones sociales y si, como muchos autores afirman, el objeto propio de la sociología es el estudio de estas relaciones, es obvio que el conocimiento acumulado por esta disciplina puede iluminar aspectos esenciales del mundo afectivo.

El modelo de la teoría sociorrelacional de las emociones, expuesta por Kemper en su obra $A$ Social Interaccional Theory of Emotions ${ }^{4}$, no considera el complejo entramado de las actividades técnicas que realizan los seres humanos, actividades vinculadas a la división social del trabajo y orientadas a la realización de la tarea, sino tan sólo sus actividades relacionales, esto es, aquéllas en las que el cumplimento de los objetivos o la satisfacción de los deseos y demandas de «un» individuo sólo pueden lograrse por la necesaria mediación de «otro». Es en este ámbito donde emergen, para Kemper, las dos dimensiones básicas de la sociabilidad, el poder y el estatus. ¿En qué posibles modos las mediaciones del individuo A pueden ajustarse a los objetivos o a las demandas y necesidades del individuo $\mathrm{B}$ ? O, dicho de otra forma, ¿Por qué hace $\mathrm{A}$ aquello que $\mathrm{B}$ quiere que haga? Como respuesta, el autor propone dos explicaciones analíticamente independientes: «bien A hace lo que quiere $\mathrm{B}$ porque está real o potencialmente coaccionado por $\mathrm{B}$ a hacer eso, o bien $\mathrm{A}$ hace lo que $B$ quiere porque A quiere hacerlo para otorgar un beneficio a $B$ » (Kemper, 1978b: 28). Esto es, o bien A está obligado por B a hacer lo que hace (dimensión relacional de poder), o bien A hace lo que hace voluntariamente (dimensión relacional de estatus).

Este modelo relacional se sustenta sobre una concreta metateoría, conocida como teoría del intercambio, y desarrollada por G.C. Homans y P.M. Blau entre otros, en la que los individuos, esencialmente separados entre sí, constituyen fuentes recíprocas de refuerzos positivos o negativos, de premios o castigos, de recompensas o privaciones. Un juego relacional de intercambio basado en el dar y en el recibir, en el que se postula el deseo de gratificacio-

3. Kemper está próximo al enfoque durkeimiano, por cuanto orienta su teoría al descubrimiento de cuáles son, y cómo operan, los factores sociales externos al individuo que evocan, condicionan o determinan sus emociones. Es una teoría de las emociones en la que la situación social se concibe como estímulo externo, y de ahí su carácter positivista. A este respecto, ver el apartado «The Stimulus Problem», Kemper (1978b: 11-20).

4. He traducido los términos Social Interaccional como «Sociorrelacional» para distinguir el enfoque del autor de aquéllos otros basados en el paradigma del interaccionismo simbólico. 
nes y la aversión a las privaciones, así como la mediación del otro en tanto condición instrumental del balance de gratificaciones ${ }^{5}$. En este contexto metateórico, Kemper entiende el concepto de estructura social como distribución desigualitaria de posiciones en los dos ejes de poder y estatus, esto es, considera ambas dimensiones en el sentido escalar, por lo que los individuos cuentan siempre con cantidades relativas de mayor o menor poder y estatus ${ }^{6}$. Kemper entiende "por poder acciones que son coercitivas, basadas en la fuerza, amenanzantes, que utilizan el castigo, etc., y que por lo tanto producen una relación de dominación y control de un actor sobre el otro. Esta definición de poder sigue más o menos la tradición de Weber, que entendía el poder como la capacidad para lograr los propios fines, incluso contra la resistencia del otro. La estructura social consiste, en parte, en las posiciones relativas de unos y otros en la dimensión de poder. El estatus, por otra parte, es una dimensión escalar que refleja la cantidad de voluntaria y no coactiva aquiescencia, aprobación, deferencia, recompensas, aprecio, apoyo emocional o financiero, incluso amor, que los actores se otorgan unos a otros. Como en el caso del poder, algunos actores reciben más estatus o menos» (Kemper, 1981: 337). Estatus, por tanto, queda definido «como un modo de relación social en el que existe comportamiento voluntario orientado a la satisfacción de los deseos, demandas, carencias y necesidades de los otros» ${ }^{7}$ (Kemper, 1978b: 378).

Cada actor, como resultado de una determinada interacción, puede recibir recompensas por obra de las coacciones que ejerce sobre el otro o puede recibir recompensas ofrecidas voluntariamente por el otro. Al mismo tiempo, ese actor participará en interacciones de las que resulte una menor cantidad de recompensas, bien porque no puede ejercer coacción sobre el otro

5. Kemper sigue el postulado expresado por G. C. Homans en «Social Behavior: Its Elementary Forms, Nueva York: Harcourt, Brace and World (1961), según el cual las emociones derivan de los resultados de la interacción social, esto es, del intercambio. Allí Homans relaciona la ira y la culpa con la violación del principio de justicia distributiva vinculado a su teoría del intercambio. Recibir menos de lo que uno cree que merece produce rabia; cuando uno extrae del intercambio más de lo que merece (siempre en comparación con otras personas), se genera el sentimiento de culpa. Con todo, el desdoblamiento dimensional de Kemper en términos de poder y estatus, y sobre todo la inclusión de éste último, no sólo enriquece su teoría, sino que también aleja al autor del paradigma del intercambio social.

6. Kemper acepta que esta visión de la estructura social no es muy común entre los sociólogos, y ha sido criticado por ello, y por su concepción de estatus, por Franks (Franks, 1989), Hoschchild (Hochschild, 1981) y Fine (Fine, 1981). Personalmente sostengo que no habla de estructura, en el sentido estructural-funcionalista, sino de dos orientaciones práctico-intencionales de estratificación operantes en el juego de relaciones sociales visa-vis.

7. Una distinción más matizada del concepto de estatus lo identifica con la estima y el cariño (siempre voluntarios), mientras que puede equipararse a prestigio o autoridad sólo cuando las recompensas asociadas se confieran voluntariamente, es decir, que el actor realmente crea que el otro las merece. 
(tiene menos poder que él), bien porque el otro está menos dispuesto a ofrecérselas voluntariamente (ha decrecido su nivel de estatus). El juego interaccional entre los actores en términos de poder y estatus es el que, según la teoría de Kemper, determina las emociones que evocarán internamente los sujetos. En este juego destacan cuatro posibles casos que corresponden a cuatro emociones negativas vinculadas a la interacción. "Un actor puede tener la sensación de que tiene, o ha usado, un exceso de poder en sus relaciones con el otro, o que ha adquirido o reclamado un exceso de estatus. Un actor también puede tener la sensación de que tiene insuficiente poder o de que recibe insuficiente estatus del otro. Esto hace un conjunto de cuatro posibilidades relacionales desde la perspectiva de un actor dado» (Kemper, 1978a: 33). El origen de estas sensaciones puede ser diverso. Por ejemplo, pueden provenir de normas sociales internalizadas por el sujeto, de sentimientos socializados en el curso de su vida o de francas malinterpretaciones de la situación, pero a cada una de esas sensaciones, esto es lo que sostiene la teoría sociorrelacional de Kemper, le corresponderá un tipo de emoción ${ }^{8}$.

Para completar el modelo, sin embargo, es necesario introducir el concepto de agencia, pues las emociones evocadas en el sujeto dependerán de la percepción que tenga acerca de quién es el sujeto responsable del exceso o insuficiencia de poder y/o estatus. Si el actor se considera a sí mismo responsable, la emoción será introyectada e intropunitiva, mientras que si el actor considera responsable al otro, la emoción será extroyectada y extropunitiva. Como puede ya imaginarse, estos resultados de exceso o insuficiencia de poder y/o estatus se consideran producto de situaciones alejadas del punto de equilibrio $y$, por tanto, dan lugar a emociones negativas o dolorosas: culpa, vergüienza, miedo-ansiedad y depresión. Las situaciones de interacción en las que el sujeto se siente con un adecuado nivel de poder y/o de estatus, dan lugar a emociones positivas, respectivamente, emociones de seguridad y/o de satisfacción ${ }^{9}$. Este conjunto de emociones pueden darse como resultado de una determinada interacción, o ser conjuntos sentimentales más estables vinculados a posiciones de poder y estatus en una relación social que perdura en el tiempo. Éstas son las emociones estructurales, que comentamos brevemente a continuación.

El sentimiento de culpa emerge, de acuerdo con esta teoría sociológica de las emociones ${ }^{10}$, de situaciones en las que el actor tiene la sensación de dis-

8. Este es quizás el punto clave que distingue el positivismo de la teoría de Kemper del inte raccionismo simbólico de otros sociólogos de la emoción, como A. R. Hoschhild. Para Kemper, una vez definida la situación social por el sujeto, han de evocarse unas determinadas emociones, y no otras.

9. Este modelo de conexiones entre situación social, definición de la situación, resultados de la interacción y emoción, más allá de su posible formalismo, tiene la virtud de mostrar una nueva vía de acceso a la realidad social por medio del estudio de las emociones de los sujetos implicados en una determinada estructura o fenómeno social.

10. Al objeto de evitar confusiones innecesarias, hay que advertir que tanto la etiqueta como el contenido semántico de los conceptos emocionales utilizados, en este caso por Kem- 
poner o de haber aplicado sobre el otro un poder excesivo. En el asesinato, el robo, la mentira o la violación un actor ha aplicado sus recursos de poder contra el otro, al objeto de obtener beneficios para sí, más allá de lo permitido por los estándares y normas que regulan y limitan el uso del poder y de la coacción en las relaciones sociales. La culpa se deriva, por tanto, de una transgresión de estos estándares morales, e implica una dolorosa autoevaluación negativa del sí mismo. Se ha causado daño al otro, bien infringiéndole estímulos negativos, bien privándole de algunas gratificaciones a las que tenía derecho, que son las dos formas posibles de ejercer el poder. El sentimiento de la culpa suele estar acompañado de remordimientos, aunque aquí es necesario advertir que «es el propio punto de vista del actor sobre su poder el que produce el sentimiento de culpa. Un observador objetivo puede estar en completo desacuerdo. La sociedad entera puede sancionar una conducta concreta, por ejemplo, matar en período de guerra, y pese a todo un individuo puede tener sentimiento de culpa» (Kemper, 1978b: 51) ${ }^{11}$. Además, el abuso de poder evoca, recíprocamente, el abuso de poder por parte del otro (del otro particular; o del otro generalizado, como en las imágenes todopoderosas y punitivas de algunos dioses), lo que explica la ansiedad asociada a la culpa y la huida como conducta típica. Así mismo, como emoción operante en la dimensión del poder, la expiación de la culpa y la reducción de la tensión asociada a ella sólo pueden lograrse mediante el castigo, que opera como contrapoder capaz de saldar la deuda ("ojo por ojo, diente por diente», en el Talión; cortar la mano al que roba, en el Corán; o controlar su movilidad y su capacidad de acción mediante la cárcel, en la sociedad moderna). En suma, a diferencia de la vergüenza, no puede haber perdón sin castigo. Sin embargo, el abuso de poder, y la culpa, puede ser también extroyectado, de modo que recaiga sobre la víctima la responsabilidad de la acción. En estos casos se generan sentimientos de ira y hostilidad (superpuestos al sentimiento de culpa), que justifican el abuso en el marco de una especie de megalomanía (superioridad del sí mismo que justifica cualquier acción de poder ejercida sobre el otro), del modo que aconteció típicamente en el régimen nacionalsocialista ${ }^{12}$.

per, sólo tienen sentido en el marco de su teoría (como, por otra parte, sucede con todos los conceptos científicos o que pretenden serlo), y no corresponden necesariamente al uso vernáculo de los mismos. Esta observación es aún más importante a la hora de entender la teoría de la vergüenza y del orgullo de Thomas J. Scheff.

11. Este punto es importante porque señala a las emociones como el mejor indicador de la posición del sujeto ante un determinado hecho. En términos de Hochschild, las emociones señalan el punto de vista del sujeto.

12. A este respecto, ver el interesantísmo artículo de Sykes y Matza (1957) acerca de las técnicas de neutralización de la culpa utilizadas por los desviados que ejercen violencia, técnicas que pueden encontrarse punto por punto en las ideologías que asisten a los movimientos terroristas, y que hacen ininteligible para muchos la ausencia de remordimientos y de sentimientos de culpa. También la desigualdad económica en una sociedad conduce a un sentimiento larvado de culpa que tiende a neutralizarse generando ideologías de supremacía moral de los ricos sobre los pobres, ver Sennett (1972). 
En la relación inversa, esto es, cuando el actor se encuentra en una posición estructural en la que dispone de insuficiente poder frente al otro, la expectativa de que el otro pueda hacer uso de su poder a voluntad hace que se perciba a sí mismo como un ser vulnerable, evocándose en este caso la emoción de miedo-ansiedad. El rol del poder en el desarrollo de la ansiedad fue reconocido por Freud, que hacía depender su aparición de diversos factores " $y$ » de la sensación de poder del individuo frente al mundo externo. «El reconocimiento de la propia insuficiencia - señala Kemper- proyecta la probabilidad de la derrota sobre las ocasiones futuras de confrontación. Esto hace el futuro incierto y carente de atractivo, idóneo para la condiciones que llevan al miedo-ansiedad» (Kemper, 1978b: 56). Si la falta de poder es atribuida a las incapacidades y deficiencias propias, el miedo-ansiedad es introyectado en lo cognitivo como la amenaza de un destino inminente, como la expectativa de algo terrible que ha de acontecer en el futuro, acompañado de la sensación de impotencia del actor para impedir estos hechos ${ }^{13}$. En su otra versión, esto es, "cuando el otro es considerado como el agente causal de la propia insuficiencia estructural de poder, la emoción sigue siendo de miedo-ansiedad, pero con un diferente resultado. Considerar al otro como responsable equivale a atribuirle la intención y la voluntad de doblegarnos con el objeto de beneficiarse. Y esto conduce - según la hipótesis de Kemper- a extroyectar el miedo-ansiedad en forma de ira y hostilidad contra el otro, en un esfuerzo por destruir, bien el poder del otro, bien las bases de ese poder» (Kemper, 1978b: 57). En el ámbito político, la forma introyectada del miedo-ansiedad lleva a la subyugación, mientras que la forma extroyectada conduce a la rebelión. La ira, el enfado, así como la expresión de sentimientos hostiles, señalan al otro nuestra disposición a usar el poder contra él, cumpliendo una importante función disuasoria (la cobardía ha sido siempre la mejor invitación al abuso de poder).

La depresión, en el marco teórico esbozado por Kemper, «resulta de un déficit de estatus, esto es, de una insuficiencia de recompensas y gratificaciones otorgadas voluntariamente por los otros (Kemper, 1978: 35). Sin duda, algunos de los más importantes bienes que anhelan los seres humanos, por no decir los más deseados, pertenecen a ese grupo especial de "cosas» que ni podemos comprar, ni podemos arrebatar por la fuerza a los demás. El uso del poder para conseguir estas cosas destruye ipso facto la magia de su atractivo, porque todas ellas tienen como inexcusable condición que sean otorgadas volunta-

13. La existencia de un síndrome de ansiedad, entendida como preocupación colectiva respecto de inciertos, ambigüos e improbables peligros que nos acechan, característica de la estructura emocional de la denominada sociedad del riesgo, y originada ante todo por la pérdida de atractivo del tiempo futuro, por la ausencia de metas y de ilusiones (optimismo propio de la modernidad), constituye la tesis central de mi investigación acerca del contenido emocional de los artículos de prensa en las sociedades post- (en el sentido literal del prefijo) modernas (Bericat, 1999). 
riamente. Esto es en esencia el estatus. Tal y como es concebido desde esta teoría, lo determinante no es el contenido de lo que los otros nos dan, sino la intención con la que nos lo dan, que ha de ser libre y sin coacciones. Por ejemplo, el reconocimiento y el respeto exigido por el poderoso lleva a conductas rituales y a simulacros de la deferencia que pueden considerase personalmente un bien muy deseado, al tiempo que un medio imprescindible al mantenimiento del orden. Sin embargo, no pueden considerarse estatus. El auténtico reconocimiento y respeto que provoca una autoridad, como la del discípulo por su maestro, el cariño y la estima que se profesan las personas en la amistad, los cuidados y las preocupaciones de los progenitores para con los hijos, o el amor de la pareja son los bienes cuya carencia nos lleva a la depresión. Aquí, como en los casos anteriores, la depresión no ha de entenderse en su sentido patológico, sino como un tipo-ideal de sentimiento tiende a surgir allí donde aparecen carencias de estatus. El caso de la pérdida de un ser querido, como pueda ser la pareja de un anciano o anciana, constituye un ejemplo claro e ilustrativo, pero extremo, de depresión. La edad conlleva una reducción de los vínculos sociales, hasta el punto de que el monopolio de las recompensas de estatus es ostentado por la pareja, por lo que su desaparición implica, de raíz, una traumática, permanente y casi absoluta pérdida de estatus estructural.

El cuarto sentimiento derivado del modelo, el de vergüenza, «es la emoción experimentada cuando un actor cree que ha reclamado y/o recibido más estatus del que merece» (Kemper, 1978: 34). Esto explica, por ejemplo, la turbación que sentimos al cometer un fallo ante los demás, pues si el estatus nos es normalmente otorgado por el reconocimiento de nuestros logros en la división del trabajo o por nuestra capacidad relacional, un fallo a la vista de los demás, sobre todo de aquellos seres que nos ofrecen estatus, les indica que no somos tan competentes, o que no somos tan buenos. En este caso tememos que reduzcan el estatus que habitualmente nos otorgan. En suma, la vergüenza o la turbación se evocan en la exposición pública, real o imaginada, de nuestra incompetencia ${ }^{14}$.

El modelo descrito ${ }^{15}$, de posiciones relativas de poder y estatus entre los actores, no sólo es utilizado por Kemper en el análisis de las emociones dolorosas que emergen de los desequilibrios, sino que también lo ha aplicado a otras emociones, como el amor, al que dedica los capítulos undécimo y duodécimo de su obra. En coherencia con su modelo, trata la emoción del amor

14. No extendemos aquí el análisis de la vergüenza de Kemper porque Scheff ha desarrollado toda su sociología de la emoción en torno a una teoría social de la vergüenza, teoría que se expone en el cuarto epígrafe.

15. La descripción del modelo ha sido la más simple entre las posibles, aunque Kemper avanza en su obra hasta formalizar un sistema muy amplio, si bien excesivamente formal, de emociones derivadas de resultados de la interacción social. Esta complejidad y amplitud no puede ser aquí siquiera referida, por lo que una comprensión cabal requiere la lectura de su obra, repleta de argumentaciones y matices metateóricos. 
en tanto relación social de intercambio, definiéndola en términos de estatus otorgado: "una relación de amor es aquélla en la que al menos uno de los actores otorga (o está dispuesto a otorgar) un sumamente alto estatus al otro» (Kemper, 1978 b: 285). El otorgamiento de estatus también puede ser recíproco, pero no podría hablarse de amor si al menos uno no estuviera dispuesto a darse al otro. En el amor, como en toda relación social, también está presente la dimensión de poder, y esto le permite a Kemper construir una interesante tipología de relaciones de amor según las posiciones relativas (altas o bajas) de poder y estatus de los sujetos ${ }^{16}$. Al margen de la presencia del poder en el amor, la condición mínima es que al menos uno de los sujetos está dispuesto voluntariamente a dar, a recompensar en alto grado al otro, hecho en sí mismo que reclama una explicación. Para Kemper, el fundamento del amor, «el principal refuerzo en la esfera del amor deriva de la armonía entre los atributos del otro y nuestros propios estándares de valor (Kemper, 1978b: 328), por lo que, «desde el punto de vista del actor que confiere estatus, el deseo de hacer eso constituye una respuesta no voluntaria» (Kemper, 1978b: 296). El enamorado/a no se da al otro y le da al otro gratificaciones por una decisión racional, sino que lo hace por un impulso interior que procede de la armonía entre algunos de sus valores y algunas de las representaciones que él mismo hace del objeto. Según Kemper, en la mayor parte de los casos es posible decidir por voluntad propia si nos comportamos hacia el otro en términos de conferirle estatus, pero no está en nuestra mano, al menos no en nuestra conciencia ni en nuestra voluntad racional, decidir si sentimos amor hacia el otro (Kemper, 1978b: 296).

Para terminar esta breve referencia, nos gustaría mostrar cómo el modelo relacional aplicado a las emociones puede distinguir entre "querer» $\mathrm{o}$ "gustar» (like), por un lado, y «amar» (love), por otro, dos sentimientos diferentes que mantienen intencional y funcionalmente un significado ambiguo en el uso corriente. En ambos casos existe concesión de estatus, pero lo que varía es la dirección relacional del flujo. Queremos a una persona, o nos gusta, cuando ella nos otorga estatus, es decir, cuando nos ofrece beneficios y recompensas de aquéllas que ni se pueden comprar ni se pueden forzar. Pero sólo amamos a una persona cuando estamos dispuestos a conferirle estatus, cuando se produce esa armonía entre sus atributos, tal cual nos los representamos, y nuestros valores (Kemper, 1989). Esta sencilla diferencia, que sólo un análisis sociológico, esto es, relacional, puede desvelar, tiene capacidad para explicar algunos fenómenos difíciles de entender. Por ejemplo, puede ayudar a explicar la distribución en la estructura social de las tasas de divorcio. $\mathrm{O}$ también, algo de lo que siempre se sorprenden los terapeutas familiares, el hecho de que mujeres que reciben intensos y reiterados maltratos por parte de su pareja, sostengan pese a todo que ellas los siguen amando. Amas cuando confieres estatus; cuando te confieren estatus, quieres.

16. Los tipos son: amor romántico, amor fraternal, amor carismático, amor infiel, encaprichamiento amoroso, amor de fans y amor paterno-materno filial (Kemper, 1978b: 285-294). 


\section{Arlie R. Hochschild: normas sociales y estructura social}

La sociología de la emoción, en la profesora Hochschild, parte de la evidencia empírica con que se manifiestan los sentimientos en la vida cotidiana de la gente, esto es, los sentimientos normales y comunes, "no sólo aquéllas olas excepcionales de emoción, como el pánico en la bolsa o en las multitudes amotinadas» (Hochschild, 1975: 285). También parte de un concepto de actor alejado tanto del supuesto agente calculador y racional, carente de emociones, como de aquél agente dominado por impulsos emocionales instintivos. Un actor social que es al mismo tiempo consciente y sentiente. Por ello, su universo de estudio son los sentimientos conscientes que participan en el juego de la vida social. Para Hochschild, practicar la sociología de la emoción es, en sus propias palabras, «teorizar sobre todo aquello que se hace evidente cuando hacemos la simple asunción de que lo que sentimos es tan importante como lo que pensamos o lo que hacemos para el resultado de la interacción social» (Hochschild, 1990: 117).

Sus referencias de contraste son E. Goffmann, quien estudia tan sólo la conducta externa de los individuos, orientada racional y calculadamente al objetivo dramatúrgico de la autopresentación en la vida cotidiana, olvidando por sistema los auténticos sentimientos de las personas, y S. Freud, que tuvo en cuenta las emociones, pero tan sólo como subproductos o epifenómenos de unos impulsos o instintos, no considerando la capacidad voluntaria y consciente del ser humano para operar sobre ellos. En ambas perspectivas, el vínculo entre emociones y estructura social deja de lado estos sentimientos, impidiendo así la aplicación de un verdadero análisis sociológico. Rechaza el modelo "organicista», que define principalmente las emociones como un proceso biológico, al estilo de S. Freud, Ch. Darwin y W. James, y se acoge a un modelo interaccional, siguiendo ideas de J. Dewey, H. Gerth y C. W. Mills, G. H. Mead y E. Goffman. «El modelo interaccional presupone la biología, pero añade más elementos de influencia social: los factores sociales no entran sólo antes o después, sino interactivamente duran te la experiencia de una emoción» (Hochschild, 1983: 211). Su modelo puede catalogarse sociológicamente bajo el amparo de dos metateorías, la del interaccionismo simbólico y la del intercambio social ${ }^{17}$. En virtud de su primera orientación, se distingue de los positivistas en su interés, no por conocer los factores sociales que provocan una emoción, sino por conocer de qué modo opera activamente el ser humano en el universo emocional. En virtud de la segunda, está interesada por la relación entre este universo y las condiciones de intercambio en el seno de una estructura social dada ${ }^{18}$.

17. Existe también una teoría socioconstructivista de las emociones, más radical que el interaccionismo simbólico a la hora de desvincular los sentimientos de su substrato biológico. Ver: Gordon (1981), así como su definición de «sentimiento».

18. Para un análisis de los modelos «organicista»e «interaccional» de las emociones, ver apéndice A, p. 201-222, en Hochschild (1983). 
En la medida que los sentimientos se consideran parte de la conciencia, no meros impulsos biológicos, queda abierto el problema de su significado, aspecto clave desde la perspectiva interaccional. Para Hochschild, las emociones están orientadas a la acción, como en Darwin, que las consideraba protoacciones, pero también están orientadas hacia la cognición. En primer término, están radicalmente condicionadas por nuestras expectativas previas. En segundo término, cumplen una función de señal, son algo así como un sexto sentido que indica la autorrelevancia para el propio actor de una situa ción dada. Las emociones reflejan la perspectiva vital del actor en sus contextos, marcando de esta manera una vía de acceso diferente para el análisis de las definiciones de la situación y, por ende, para el análisis social ${ }^{19}$. Hochschild relaciona en su sociología de las emociones: experiencia emocional; gestión emocional; normas emocionales; estructura social, e ideología (Hochschild, 1979).

Las emociones están cargadas de significados, de sentidos anclados en unos específicos contextos sociohistóricos, contextos entre cuyas dimensiones merece la pena señalar la dimensión normativa, la dimensión expresiva y la dimensión política (Hochschild, 1975: 288). La primera se fundamenta en el hecho de que las normas sociales no sólo se aplican a la conducta y al pensamiento, sino también a las emociones. Podemos hablar, entonces, de la existencia de «normas emocionales» (feeling rules). Las situaciones sociales inducen un conjunto de emociones en los actores, pero también incorporan controles que afectan a sus sentimientos. Las normas emocionales constituyen un modo de control social que definen lo que debemos sentir en diversas circunstancias, indicando cuál es el sentimiento apropiado y deseable en cada caso. Estas normas resultan apenas perceptibles cuando sentimos lo que debemos sentir, pero se manifiestan en forma de disonancia cuando nuestros sentimientos se desvían de lo indicado por la norma. Debemos estar alegres en las fiestas y tristes en los funerales. Las normas indican la intensidad, la dirección y la duración del sentimiento. Un legítimo enfado, por ejemplo, se puede prolongar más allá de lo que determina la norma; puede ser inapropiado por su excesiva o escasa intensidad; o incluso no estar justificado en absoluto en esas circunstancias, a las que correspondería normativamente otra emoción. La legitimidad de un sentimiento puede ser de tres clases, clí nica, moral y sociosituacional. En la primera el sentimiento se desvía de lo que puede ser el rango de emociones de un actor normal o sano; en la segunda el juicio afecta a la legitimidad moral de sentir o no sentir algo; en la tercera se atiende al lugar y situación concreta en que el actor está sintiendo o manifestando una emoción. La cultura, pese al escaso interés mostrado has-

19 "Los sentimientos nos dicen "qué hay allí afuera desde donde estamos"» (Hochschild, 1990: 119), comunican información al sujeto sobre el mundo exterior, sea natural, social o personal, desde su propia perspectiva. En este sentido podemos considerar que las emociones constituyen un dato absoluto, del que no puede prescindir el análisis social, ni micro ni macrosociológico. «Siento, luego existo». 
ta ahora por los sociólogos, está plagada de normas emocionales que regulan qué, cuando, cómo y cuanto debemos sentir.

Pensando en el carácter protoactivo de las emociones, no ha de extrañarnos que el control emocional constituya una clave relevante del control social, un modo de participar en la constitución del orden social. De ahí que cuando el actor sienta una emoción distinta a la establecida por la norma, también sentirá el efecto de la disonancia o desviación emocional. Los demás suelen dejar claras muestras de tal disonancia cuando te señalan, por ejemplo, "que no tenías derecho a enfadarte así», "que no debes sentirte tan culpable», «que deberías estar más contento» o «que tus celos son absurdos». El pinchazo de la disonancia espolea gestiones emocionales por parte de los actores, es decir, no sólo "sentimos algo" sino que también "tratamos de sentir algo", hacemos esfuerzos por modificar nuestros estados emocionales. El concepto de gestión emocional (emotion management o emotion work) «refiere las acciones por las que intentamos modificar el grado o la cualidad de una emoción o sentimiento" (Hochschild, 1979: 561). Esta gestión no es, sin embargo, como en otras teorías, mera supresión o represión de sentimientos indeseables, sino también en muchos casos evocación o estimulación de determinados sentimientos deseables pero inicialmente ausentes. En un estudio empírico en el que se pedía a los sujetos recordar y comentar algún episodio emocional de sus vidas, se puso de manifiesto tanto la disonancia normativa que afectaba a la mayor parte de episodios narrados, como los esfuerzos y las técnicas utilizadas por los sujetos para modificar sus estados emocionales.

Al igual que existen normas emocionales, también existen «normas de expresión emocional» (expression rules) que señalan al actor qué emociones, hasta qué grado y en qué circunstancias pueden ser expresadas. El actor aquí se somete a una mera constricción externa de la conducta que deja intactos sus auténticos sentimientos. En la vida cotidiana, muchos de los comentarios que recibimos de los otros, refieren exclusivamente la conveniencia o no, la justificación moral o no, de mostrar una determinada emoción en un específico contexto social y a unas personas concretas. Las emociones, que de una parte señalan la auténtica perspectiva vital del sujeto, entran también en el juego de la vida social como emociones comunicadas, abriendo así la puerta de la inautenticidad ${ }^{20}$. El control opera en muchas ocasiones sobre la máscara emocional, dejando libertad al individuo para sentir en sus adentros lo que buenamente quiera.

En el caso anterior estamos sólo ante un cambio exterior de la conducta

20. No puede infraestimarse la distinción entre experiencia emocional y expresión emocional, así como sus conceptos afines. Por ejemplo, la "neutralidad afectiva» que parece caracterizar algunos ámbitos sociales, es producto de la aplicación de férreas normas de continencia expresiva, antes que síntoma de una absoluta ausencia de emociones. Metodológicamente implica que es preciso tener en cuenta las sutiles formas en que la emoción es comunicada. En culturas expresivas la emoción es obvia, pero ello no significa que no esté presente en culturas menos expresivas. 
expresiva. Sin embargo, cuando Hochschild habla de gestión emocional se refiere a un cambio real en los sentimientos, modificación que puede obtenerse por dos diferentes métodos. El primero se denomina «actuación superficial» (surface acting), en la que el sujeto utiliza un cambio de expresión como medio para modificar sus sentimientos reales. El segundo, o «actuación profunda" (deep acting), se basa en modificar directamente el sentimiento por medio de cambios en nuestro foco perceptivo sobre la situación, o por acciones fisiológicas, como puede ser respirar profundamente para calmarse. El segundo tipo de gestión puede asimilarse a los consejos que Constantin Stanislavski daba a sus alumnos para generar un sentimiento autoinducido, pues al actor no le bastaba con expresar las emociones, sino que, en su opinión, debía experimentarlas realmente (Hochschild, 1983: 35-55). En suma, el actor no sólo cuenta con sus experiencias emocionales, y con la comunicación de sus sentimientos como modo de intercambio social, también puede, y habitualmente lo hace, operar sobre sus emociones, por cualquiera de los dos métodos disponibles.

En su dimensión política, las emociones están vinculadas a sanciones sociales, así como al entramado de la estructura social. Por ejemplo, en el caso de la envidia, se da la circunstancia de que su contención normativa se aplica a todos por igual, mientras que las condiciones sociales de su evocación están desigualmente distribuidas. En el caso de la rabia, la ira o el enfado también operan normas emocionales, pero en la práctica estos sentimientos suelen tener como destino u objetivo gentes con un menor nivel de poder social. A diferencia de la envidia, la rabia circula por canales de menor resistencia, va de arriba a abajo, y no de abajo a arriba. Así mismo, se puede detectar una jerarquía del humor y de las bromas, utilizadas más frecuentemente por aquéllos que ocupan posiciones sociales más altas. Los poderosos disponen de adecuadas barreras y frenos contra la expresión de hostilidad por parte de los otros, "los poderosos no sólo obtienen una cantidad desproporcionada de recursos como dinero o prestigio, sino que también disfrutan de más recompensas afectivas»; «En consecuencia, los poderosos y quienes carecen de poder viven diferentes mundos, no sólo físicos y sociales, sino también emocionales» (Hochschild, 1975: 297).

Un ejemplo de esta relación entre emociones y estructura social es el fantástico estudio publicado bajo el título The Managed Heart. Commercializa tion of Human Feelings, en el que se avanza desde la lógica del orden emocional en el ámbito del mundo privado, hasta su institucionalización en el ámbito socioeconómico del trabajo. Se trata de un estudio sobre los requerimientos profesionales, de carácter emocional, de las azafatas o asistentes de vuelo que trabajan para las compañías aéreas. Aquí se evidencia que el trabajador, sobre todo en determinadas ocupaciones del sector servicios, no vende esencialmente fuerza física, como en los orígenes de la industrialización, ni vende conocimiento o capacidad racional, como en una fase posterior, sino que vende también sus emociones. Existe por ello riesgo de alienación y extrañamiento, como bien señaló C. Wright Mills al sostener que cuando 
«vendemos nuestra personalidad al vender bienes o servicios nos implicamos en un grave proceso de autoextrañamiento, proceso cada vez más común entre los trabajadores de los sistemas capitalistas avanzados» (Hochschild, 1983).

El sistema emocional que opera en el trabajo no es ya el mismo conjunto de normas emocionales, modos de gestión emocional e intercambio social que aplicamos en nuestra vida privada. El sistema sufre en sus tres elementos una transmutación condicionada por los imperativos de la lógica económico-productiva, en este caso. En primer lugar, «la gestión de las emociones deja de ser un acto privado y pasa a ser un acto público, comprado en un lado y vendido en el otro». Ya no es un intento espontáneo de modificación (emotion work), sino un plan predeterminado y coactivo (emotion labor); deja de ser una gestión emocional privada, y pasa a ser un trabajo emo cional público. En segundo lugar, «las normas emocionales ya no cuentan con la discrecionalidad propia de la negociación con los otros en un ámbito privado, sino que están formalmente publicadas» en manuales de la compañía, en guías profesionales, en programas de entrenamiento, así como en la misma publicidad. Una señorita guapa, amable y sonriente es el modelo de relación emocional que se transmite como estereotipo y como norma de trabajo. En tercer lugar, el sistema se caracteriza por un intercambio social que circula por canales estrechos; puede haber lugares escondidos a lo largo del pasillo, pero hay mucho menor margen para la navegación individual por las aguas emocionales» (Hochschild, 1983: 118-119). El trabajo emocional público predomina sobre el privado, que circula ahora por una corriente subterránea. El trabajador debe controlar sus emociones, pero las compañías le piden, además, no sólo una actuación superficial, sino una profunda, no sólo que sonrían, sino que sientan la amabilidad que ofrecen y que disfruten con la sonrisa.

Las/os asistentes de vuelo tienen que aprender a comportarse personalmente en relaciones de por sí impersonales; tienen a veces que soportar los enfados o las bromas de los clientes; tienen que reprimir en todo caso sus propios enfados, y tienen que sonreír y ser amables. La sonrisa, que en el ámbito privado y en el marco de la autenticidad es una señal de placer, alegría, divertimento, amistad, etc., es separada de su función habitual de expresar un sentimiento personal y vincularnos al otro, y pasa a ser la expresión del sentimiento de la empresa (Hochschild, 1983: 127). El trabajador se enfrenta al dilema de la "falsa sonrisa», oponiéndose también a los planes de la compañía en una especie de guerra de la sonrisa. En todo caso, parece evidente que el trabajo emocional es un componente básico de los requerimientos laborales de muchos puestos de trabajo en las sociedades de servicios, un esfuerzo y un trabajo donde, a diferencia de la vida privada, impera la norma de la inautenticidad, configurando personalidades alienadas que entran en conflicto consigo mismas.

El caso de las/os asistentes de vuelo no es el único y, como punto de contraste, puede mostrarse el sistema emocional de otras ocupaciones, como 
por ejemplo los cobradores de morosos. «El proyecto de las asistentes de vuelo es realzar el estatus del cliente, elevar su importancia; «el pasajero puede algunas veces no tener razón, pero nunca se equivoca». Cada acto de servicio es un anuncio publicitario. Al contrario, las escenas finales del cobro de morosos acaban generalmente reduciendo el estatus del consumidor, conforme el cobrador de morosos trabaja desgastando la presumible resistencia del consumidor a pagar» (Hochschild, 1983: 139). El cobrador puede llegar a humillar al consumidor, sobre todo cuando está ante una persona que no reconoce su vergüenza, lo que suele acompañarse con las respuestas de ira que tantas veces tienen que soportar estos trabajadores de la "cara de perro» (para reducir en lo posible estas expresiones de ira y hostilidad), y de la proyección de "vergüenza» (para cobrar cuanto antes sin llegar a las etapas finales, emocionalmente más duras) ${ }^{21}$. En cualquier caso, trabajo emocional regulado y comprado al que se ven sometidos, con mayor o menor intensidad, de una u otra manera, un 38,1 \% de todos los empleos de Estados Unidos en el año 1970, siendo este porcentaje del 55,2 \% para las mujeres, y del 27,7\% para los hombres. Ocupaciones como médicos, vendedores, dependientes, camareros ${ }^{22}$, abogados, clérigos, relaciones públicas, profesionales de los medios de comunicación, profesores, secretarias, etc., etc., se parecen en la necesidad de realizar trabajo emocional. En conjunto, un 61,6 \% de todos los empleos existentes en ocupaciones del sector servicios, siendo un $81,3 \%$ para las mujeres, y un 37,6 \% para los hombres (Hochschild, 1983: 234-242).

El estudio de las emociones también puede orientarse hacia el análisis del sistema emocional que portan las ideologías, ancladas en distintas posiciones de una estructura social y, por tanto, asociadas a distintos modelos o patrones de intercambio. Una determinada cultura emocional contiene, «además de las normas emocionales, creencias acerca de las emociones (como «el amor dura siempre» o "una persona puede morir de pena»), y nociones acerca de cómo debemos atender, codificar, apreciar, gestionar o expresar los sentimientos. La cultura emocional queda reflejada en libros de consejos, películas, tratados religiosos, teorías psiquiátricas o leyes (por ejemplo, qué constituye un crimen pasional) (Hochschild, 1990: 124). Y se refleja ideológicamente de acuerdo con modelos vinculados al orden de las castas o de las clases sociales, al de los grupos étnicos o a los del género. A este último ámbito de estudio, es decir, al análisis de la estructura emocional de la exis-

21. Es obvio que sistemas aplicados por las empresas de morosos, como «El cobrador del frac», se basan en la proyección de vergüenza sobre la red de relaciones sociales del moroso. Tratan de cobrar sin el recurso a la fuerza "física», utilizando en cambio el recurso de la «fuerza emocional».

22. En el caso de camareros y, en general, de los trabajadores de la hostelería, cuyas condiciones de trabajo y vida estoy investigando a través de grupos de discusión, es claro el tremendo coste de trabajo emocional que conlleva. Dado que su nivel de estatus comparado con el del cliente suele ser bastante inferior, la interrelación emocional en estos casos es aún más dolorosa, a veces humillante, como así es expresado en los mencionados grupos. 
tencia cotidiana de los géneros en el seno de la institución familiar, Hochschild ha dedicado dos investigaciones publicadas bajo los títulos The Second Shift y The Time Bind.

En la primera analiza las tensiones emocionales y las ideologías de género en parejas en la que ambos miembros trabajan, parejas en las que se acrecienta la necesidad de negociar quién, y en qué proporción, hará el «segundo turno", esto es, el trabajo de la casa. Analiza los roles maritales, a los que los miembros traen ideologías de género similares o conflictivas, así como nociones de lo que un marido y una mujer "debe a" y "merecen de» uno de otro. Analiza el coste emocional de las estrategias de género según el cruce de tres posibles ideologías, una tradicional, otra igualitaria y otra de transi ción (Hochschild, 1990: 125). "La combinación de las ideologías de género de los actores, y el resultado real de la interacción de la estrategia de cada miembro parecen determinar sus sentimientos acerca de la división del trabajo en casa». Por ejemplo, frustración, con límites normativos para la expresión de la ira, en suma, resentimiento, en las mujeres con ideales igualitarios de género cuyos maridos rechazan compartir el trabajo del hogar (Hochschild, 1990: 132). La economía de la gratitud o intercambio de dones en los que se basa la pareja también queda afectada, y con ella los sentimientos. Una flor, que trae el esposo, o un pastel de manzana que cocina la esposa, pueden producir emociones diferentes a las esperadas tras un regalo. Las tareas de la casa, así como el trabajo externo, salen de la economía de la gratitud o del intercambio de dones, y pasan a ser exigidos como deberes u obligaciones, alterando de esta forma la evocación emocional (Hochschild, 1989a y 1989b).

Un análisis similar de la estructura emocional de la familia, en The Time Bind, tenía ahora por objeto analizar la atención que los padres que trabajan prestan a sus hijos y el tiempo disponible para estar con ellos. Este "tercer turno", el de atención a los niños, como lo denomina Hochschild, se impone agotando casi en su totalidad el "tiempo de familia», es decir, transmuta este tiempo en un tiempo de estrés, de trabajo emocional, de planificación de tareas, asemejándose cada vez más al tiempo de trabajo productivo. Si la imagen emocional típica del hogar es dulce y relajante, el antiguo descanso del guerrero, en estas familias al menos «casa» $y$ «trabajo» invierten su sentido emocional. Ahora es en la empresa donde las personas obtienen reconocimiento, donde se estimula y se recompensa, donde se mantienen las relaciones sociales más ricas y enriquecedoras. Y esto explica, en parte, por qué los trabajadores apenas hacen uso de las políticas de flexibilización y reducción del tiempo de trabajo que tienen a su disposición en la empresa. El tiempo de familia, y su lugar social correspondiente, la casa, están dejando de ser un mundo emocional atractivo (Hochschild, 1997). 


\section{Thomas J. Scheff: vínculos sociales seguros e inseguros ${ }^{23}$}

En opinión del profesor Scheff, todas las teorías sociales contienen en su interior, más o menos explicitados, unos presupuestos metateóricos acerca de la naturaleza humana y de sus fuentes de motivación. La teoría sociológica de la vergüenza de Scheff también parte de un supuesto motivacional que la inspira. Este supuesto nos propone que «el mantenimiento de los lazos o vínculos sociales es el más crucial de los motivos humanos» (Scheff, 1990: 4). Como su principal corolario surge una imagen de las relaciones sociales en la que los seres humanos, en todos y cada uno de sus encuentros, se enfrentan a una situación en la que su vínculo social con el otro es «construido, mantenido, reparado o dañado» (Scheff, 1994: 1). Cada contacto abre estos cuatro, y sólo estos cuatro, posibles resultados de la interacción social en términos del más básico de los motivos humanos.

El establecimiento, mantenimiento, mejora o dañado de nuestros vínculos sociales hace referencia a una clase especial que Scheff denomina "vínculos seguros» (secure social bond). Son aquéllos en los que el individuo mantiene respecto del otro una adecuada distancia social, ni demasiado estrecha ni demasiado holgada. Esa distancia óptima de interacción donde el individuo ni es anulado o engullido por la relación o el grupo, ni tampoco se encuentra totalmente aislado. Constituye en esencia un balance entre la infradiferenciación y la supradiferenciación del individuo respecto del gupo. «Una óptima diferenciación implica cercanía porque requiere cierto conocimiento del punto de vista del otro. Pero también implica distancia, la aceptación del otro como un ser independiente de mí. Un vínculo social intacto no implica necesariamente acuerdo, pero sí conocimiento y aceptación de acuerdos y desacuerdos», «implica ser capaz de mantener lazos con otros que no son tú mismo», e «implica mutuo entendimiento que sea no sólo mental sino también emocional» ${ }^{24}$ (Scheff, 1990: 4-5). En los vínculos inseguros, a la inversa, el individuo está en uno de estos dos casos posibles, o bien a demasiada distancia social del otro, o bien a demasiada poca, es decir, bien en una situación de "aislamiento de» (isolation), o bien en una de "absorción por» (engulfment) la relación o el grupo ${ }^{25}$. En el primer caso el individuo se constituye como un yo autónomo, diferenciado y potente, pero adolece de ade-

23. He ordenado lógicamente la estructura de la teoría sociológica de la vergüenza para facilitar tanto la comprensión como una exposición sucinta. En realidad, la génesis y el desarrollo de la teoría nada tiene que ver con esta ordenación, es desde luego más laboriosa $\mathrm{y}$, hasta cierto punto, inversa al curso de exposición que aquí se ha adoptado.

24. El vínculo social seguro está relacionado con un estado de attunement, un estado de sintonía o armonía que no implica necesariamente consenso, pero sí comprensión y reconocimiento de los diferentes puntos de vista y posiciones de los sujetos. Ver capítulos 3, 4 y 5 en Scheff (1997).

25. La idea de aislamiento (isolation) y absorción (engulfment) procede de M. Bowen (1978), Family Therapy in Clinical Practice. Nueva York, Jason Aronson. Bowen es uno de los fundadores de la teoría de los sistemas de familia. 
cuadas ligaduras con el otro, está aislado ${ }^{26}$. En el segundo caso, la distancia social casi queda anulada, y el individuo es engullido por el grupo, no dejándole constituir una entidad diferenciada. El individuo desaparece sumido, inmerso o absorbido por la relación o el grupo. Partes esenciales de su individualidad, como pensamientos, creencias o valores, son sacrificados en aras del grupo. En suma, los vínculos seguros establecen la única forma de soli daridad que lleva a la cooperación, "son la fuerza que mantiene una sociedad unida» (Scheff, 1990: 4). Los vínculos inseguros, al contrario, señalan dos formas de alienación, aislamiento y absorción, que pueden llevar a la desintegración y al conflicto.

Esta tipología de vínculos encuentra su origen y reflejo en la propia teoría del suicidio de E. Durkheim ${ }^{27}$. El suicidio egoísta emerge en contextos culturales y societarios donde predomina el individualismo y la falta de adecuados lazos sociales. El suicidio altruista, al contrario, aparece allá donde se exige al individuo una lealtad total, donde el yo está tan íntimamente unido al grupo que no es sino un adminículo suyo. Para Scheff, como para el mismo Durkheim, estos dos estados del vínculo social son patológicos, y no sólo conducen a una más alta tasa de suicidios, sino que también ponen en riesgo la supervivencia de la propia sociedad. Una sociedad absorbente no deja lugar a la crítica ni a la manifestación de puntos de vista alternativos, lo que dificulta los procesos de adaptación que toda sociedad en cambio requiere. Una sociedad atomizada en individuos aislados pone en riesgo el entendimiento cognitivo y la sintonía afectiva necesarias para la colaboración y la movilización comunitaria.

¿Por qué es la vergüenza, en opinión de Scheff, la emoción social por antonomasia?, ¿de dónde deriva su importancia a la hora de explicar el orden social, sea pacífico o conflictivo? Scheff sostiene, siguiendo la estela teórica de Ch. H. Cooley, que la vergüenza y el orgullo son las emociones sociales básicas porque ambas señalan al individuo el estado del vínculo social. Sentimos orgullo ${ }^{28}$ cuando nuestra relación con el otro es segura, no corre el riesgo de perderse o fallar, el lazo es firme, y hace que nos sintamos tranquilos y confiados. Podemos sentir vergüenza en dos casos. Cuando nuestro vínculo está amenazado o es inseguro, cuando nos sentimos rechazados, esto es, distanciados de los demás, o cuando decrece nuestra valoración en la autoimagen

26. El concepto de ligaduras es tomado y utilizado aquí en el sentido expuesto por R. Dahrendorf en su obra Oportunidades vitales. Éstas integran a su vez una adecuada combinación de opciones y ligaduras.

27. El conjunto de la obra de Scheff no es sino un diálogo permanente con la obra de E. Durkheim, a quien complementa mediante la inclusión de las emociones en un esquema metateórico similar.

28. Hay dos diferentes apreciaciones morales del orgullo. Una está asociada al orgullo excesivo, al injustificado o a la soberbia. Pero este orgullo no constituye sino una forma de aislamiento y distanciación. El orgullo legítimo, por el contrario, es el que sentimos en la armonía de apreciaciones mutuas entre dos personas, sean amigos, pareja, discípulo o alumno. Ese orgullo es el que marca el estado seguro del vínculo. 
que nos formamos desde la perspectiva del otro. Por ejemplo, cuando uno espera la llamada de sus amigos para salir el sábado y el teléfono no suena. También sentimos vergüenza, en segundo lugar, cuando estamos fundidos o sumidos en la relación, cuando no existe espacio para la autonomía y para la diferencia. Por ejemplo, cuando el adolescente sale a comprar ropa con su madre y le impone su gusto frente a lo valorado y aceptado en el grupo de amigos. Ambos casos pueden interpretarse como una doble manera de faltar al respeto debido hacia el otro, de no mostrarle el adecuado nivel de deferencia.

Así pues, la vergüenza es la emoción que regula el estado de nuestros lazos sociales. Y surge también en un contexto social, en el dominio de la dimensión intercomunicativa del ser humano. Charles Horton Cooley fue el primero en formular una mecánica de sociabilidad que incluía en el modelo un componente afectivo. Cooley, condensando su concepción del yo social o yo-espejo, en una cita ya clásica, señaló: "Una autoidea de este tipo (el yo social) tiene tres elementos principales: la imaginación de cómo aparecemos ante la otra persona; la imaginación del juicio de ésta sobre tal apariencia, y una especie de autosentimiento, como orgullo o mortificación» (Cooley, 1902: 152). Es decir, hay un juego de percepción cognitiva, un juego de valoraciones, y finalmente su transmutación en un juego de emociones. Cuando el otro nos ve bien, nos halaga, o pensamos que nos ve bien o nos halaga, siempre en términos relativos a unos determinados valores, nos sentimos bien, legítimamente ogullosos de la persona que somos, por eso contentos. Pero cuando imaginamos que el juicio del otro es negativo, o somos sometidos a la vejación del ridículo o del insulto, entonces sentimos vergüenza, un sentimiento que nos mortifica, un sentimiento que duele. Esto es, «la vergüenza es la emoción social por antonomasia en tanto surge de la supervisión de nuestras propias acciones mediante la percepción del yo, de la persona, desde el punto de vista de los otros» (Scheff, 1990b: 281).

La fuerza de esta emoción en los encuentros sociales cara a cara se muestra una y otra vez en los mil episodios de interacción que describió otro gran sociólogo, Ervin Goffman. En 1956 publica un artículo en The American Journal of Sociology, titulado "Embarrasment and Social Organization», donde señala un sentimiento de la familia de la vergüenza, concretamente la turbación, el estar en una situación embarazosa, como una amenaza presente en todo contacto social: "parece no existir encuentro social que no pueda llegar a ser embarazoso para uno o más de los participantes» (Goffman, 1956: 265). Los actores, mirados desde esa perspectiva, andan siempre ocupados en la tarea de salvar la cara, de evitar la turbación y lograr el adecuado nivel de deferencia (Goffman, 1970). Cuando un niño ya mayor se suelta de la abrazadera mientras monta los caballitos infantiles, está sintiendo vergüenza. Cuando un estudiante que trabaja en una pizzería es visto por sus compañeros es posible que sienta vergüenza. Cuando en un establecimiento público entramos en el servicio incorrecto, es posible que sintamos vergüenza o que provoquemos la risa ${ }^{29}$. 
El problema de la vergüenza, sin embargo, es que nos avergonzamos de estar avergonzados, y así sucesivamente en una espiral afectiva. Esta es una de las razones por las que, pese a lo que cabría esperar de las ideas de Cooley y de los análisis de Goffman, la vergüenza es una emoción de baja visibilidad. En primer lugar, el uso y significado vernáculo del término vergüenza es mucho más restrictivo del que se deriva de esta teoría sociológica. Incluso es un término que parece sólo aplicable a fenómenos de la niñez, pues sólo a los niños se les permite estar avergonzados. Sin embargo, todo lleva a pensar que la vergüenza está tan presente en los niños como en los mayores, si bien negada en mayor medida y reprimida con más fuerza en los adultos. La sociedad moderna, en opinión de Scheff, reprime sistemáticamente esta emoción. Basada desde el origen en la ruptura de ligaduras sociales, cimentada sobre el mito del individualismo, esta sociedad ha negado y reprimido la vergüienza por cuanto en sí misma pone de manifiesto y recuerda la falsedad del mito, es decir, la imagen de una sociedad compuesta por individuos perfectamente autónomos que no suspiran por un vínculo social seguro (Scheff, 1990: 12$)^{30}$. Un cuarto rasgo que condiciona la baja visibilidad de esta emoción es que constituye en realidad, no una única emoción, sino una familia emocional, en la que se incluyen el pudor, la timidez, el ridículo, la turbación, la humillación y otras muchas variantes.

De las razones aportadas se deriva el hecho de que la vergüenza, aún estando presente, no pueda ser fácilmente reconocida ni por el propio sujeto, ni por un observador externo. De ahí la necesidad de una fenomenología de esta emoción. En todo caso, lo importante es tener presente que la vergüenza evoca sentimientos dolorosos, autoinfringidos, procedentes de una auto-evaluación negativa realizada por el sujeto desde la perspectiva del otro, otro presente o ausente, concreto o generalizado. El gesto prototípico de la vergüenza es bajar la vista o cubrirse la cara con las palmas de la mano. También en el discurso oral o escrito pueden encontrarse indicaciones directas, como los términos "humillado» o "avergonzado», pero no es esto lo más frecuente. A veces se expresa en símbolos de abandono, separación o aislamiento, marcando así el contexto social de su evocación. A veces refieren situaciones de ridículo, aquéllas donde el sujeto es rebajado drásticamente en la valoración social por incompetencia manifiesta, la de un tonto, la de un payaso o la de una persona "absurda». También en las que el sujeto se muestra incapaz ante los otros, inepto, impotente, inferior, inseguro, sin mérito,

29. Goffman nunca trató directamente las experiencias emocionales de los actores, aunque estaban siempre implícitas en sus análisis. Tan sólo describió e interpretó las conductas externas de los actores, como las que se activan en los ritos de paso que acompañan a la entrada en una institución social (humillación), o como las conductas, expresivas, de las personas que se encuentran con otras que muestran un estigma físico diferente (horror).

30. El mito del individualismo también tiene efectos epistemológicos en las ciencias sociales, y conduce a visiones simplistas de la realidad humana, ajenas a la compleja sociabilidad inscrita en ella desde el origen (Scheff, 1990: 12). 
etc. Otras señalan la ansiedad genérica asociada a la vergüenza, a la que pueden referirse diciendo "haber pasado un mal rato» o "qué desasosiego». Por último, también se encuentran signos de vergüenza en los olvidos momentáneos, en el hecho de quedarse con la mente en blanco o en la experiencia de la pura confusión ${ }^{31}$.

La emoción de la vergüenza, así entendida, en el marco de una perspectiva sociológica, constituye un componente necesario a una teoría del control social factible. Según Durkheim, los hechos sociales debían ser considerados como cosas, y sostenía esta afirmación señalando dos rasgos básicos; uno, su exterioridad (la sociedad trasciende al individuo), y dos, su carácter coactivo (la sociedad se impone al individuo). Sin embargo, Durkheim nunca explicó por medio de qué misterioso mecanismo la sociedad conseguía imponerse al individuo. El hecho es que el individuo se ajusta a las normas sociales, a los valores, a las creencias, a los mitos y a los ritos, pero decir eso no basta para demostrar la eficacia compulsiva de lo social. Un tratamiento puramente conductual o cognitivo de la cultura no puede resolver el problema. Para Scheff, «nuestros pensamientos y percepciones de las expectativas sociales sólo instalan el escenario del control social. Experimentamos el sistema tan compulsivo debido a las emociones -el placer del orgullo y de la camaradería, de una parte, y el castigo de la turbación, de la vergüenza o de la humillación, de otra» (Scheff, 1988: 396). La deferencia, el respeto asociado al orgullo legítimo, y la vergüenza forman un sutil, pero eficaz y permanentemente activo sistema de control social, que explica por qué los individuos se someten. A una pasión sólo puede oponérsele otra pasión. Mantener la dignidad y el respecto y evitar el dolor de la vergüienza, es lo que hace operativo, en el individuo, el sistema de control como sistema motivacional o de fuerza. El salto de pasar de fuera a adentro queda ahora explicado por el efecto que tienen los otros, vía imaginaciones de sus juicios, en el contenido emocional del sujeto.

Pero la teoría sociológica de la vergüenza, en principio conectada a una teoría del control ${ }^{32}$, amplía su alcance cuando sirve también de sustento a una teoría del conflicto social ${ }^{33}$. De este modo, como era de esperar, la más bási-

31. Esta clasificación de indicios lingüisticos, orales y escritos, de la vergüenza pertenece a Suzanne M. Retzinger. Ver: Retzinger (1995: 1108).

32. La teoría sociológica de la vergüenza, conectada a la teoría del control social, se encuentra sintetizada en Shame and Conformity: The Deference-Emotion System, (Scheff, 1998) y (Scheff, 1990: 71-95), y constituye el grueso de las primeras obras de Scheff, entre las que se incluyen la teoría socioemocional de la enfermedad mental, ver Scheff (1966) y Thoits (1985), y teoría socioemocional del ritual, comprendido en tanto función catárquica teatralizada de una situación que evoca angustia, y en la que los individuos participan desde una adecuada distancia emocional, una distancia en la que el espectador ni se deja absorber por las emociones ni permanece emocionalmente ajeno al drama, es decir, una distancia estética que le permite oscilar entre las posiciones de participante involucrado y de observador externo (Scheff, 1977 y 1979).

33. El grueso de la última parte del trabajo teórico de Scheff, realizado en colaboración con Suzanne M. Retzinger, se ha orientado a la teoría del conflicto social y a los modos de 
ca de las emociones sociales está presente tanto en el orden social pacífico como en el conflictivo. Tanto el trabajo de Scheff como el de Retzinger se ha orientado al análisis de una específica cadena emocional, de vergüenza-ira o de vergüenza-enfado (shame-anger) detectada en los conflictos sociales. En esta aproximación teórica se invierte la dirección causal habitualmente mantenida, es decir, se sostiene que el conflicto no es el que produce la ruptura de los vínculos sociales, sino que, tal y como afirmó Simmel, es la ruptura del vínculo social la que provoca el conflicto (Scheff, 1994). Helen B. Lewis fue quien detectó en primer lugar que la vergüenza solía ir asociada a secuencias emocionales, detentando al mismo tiempo que en muchas ocasiones a la vergüenza evocada seguía casi sin solución de continuidad accesos de ira o enfados (Lewis, 1971). En el marco de la teoría de los sistemas familiares, Scheff y Retzinger realizaron microanálisis de grabaciones videográficas de conversaciones entre miembros de parejas con historial conflictivo. En estas grabaciones localizaron episodios hostiles, y analizaron décima a décima de segundo las intercomunicaciones precedentes, tanto lingüísticas como gestuales, para encontrar el origen del episodio. En todos ellos, ésta fue la conclusión, encontraron como antecedente próximo una situación evocadora de vergüenza, una ruptura o una amenaza del vínculo social, una falta de deferencia o respeto, unas maneras despreciativas, una falta de consideración o estima, o un franco aunque a veces larvado insulto. Lewis había denominado a estas formas de agresión humiliated fury, es decir, enfados que no derivan de una voluntad de hacer daño al otro por el propio interés, sino que, paradójicamente, proceden del sufrimiento causado por el deterioro de nuestro vínculo social con el otro. La mayor parte de nuestros enfados, en opinión de Scheff, corresponden a este tipo, como bien puede comprobarse por una atenta introspección personal. Nos enojamos, por ejemplo, si transcurre demasiado tiempo sin que el otro se dirija a nosotros cuando conversa con un reducido número de personas, entre las que nos encontramos. Nos enfadamos ante el insulto, no con la voluntad primaria de hacer daño al otro, sino más bien con el objeto de ocultar el rechazo, de evitar el dolor de la vergüenza. Si esta emoción señala una amenaza o un daño al vínculo, una separación, la agresión subsiguiente es un símbolo de la aceptación de esa ruptura, de esa distancia. Si tú te alejas, yo me alejo, proceso que contiene en sí una muy probable retroalimentación.

Ahora bien, no toda vergüenza lleva al conflicto (Retzinger, 1991: 57). La vergüenza reconocida explícitamente por el sujeto implica un reconocimiento

alienación que llevan al conflicto. Los estudios, realizados mediante la aplicación de análisis microscópicos, segundo a segundo, tanto de discursos orales y escritos como de grabaciones videográficas, se ha aplicado tanto al ámbito microsociológico (Retzinger, 1991; Scheff y Retzinger, 1991), como al macrosociológico (Scheff, 1994), estudios realizados siempre desde una orientación metodológica, el part/Whole analysis, que pretende vincular las partes más pequeñas de la interacción social con los todos más grandes (Scheff, 1997). 
del otro, una muestra de deferencia y respeto hacia el otro, por lo que el sistema puede reequilibrarse mediante una adecuada reparación del vínculo, por ejemplo una auténtica disculpa o una solicitud de perdón, no sólo expresada sino también sentida (Scheff, 1994: 127-150) ${ }^{34}$. Sin embargo, cuando la vergüenza es negada o reprimida, las posibilidades de entrar en un círculo vicioso de falta de respeto y consideración son muy altas. Entonces la vergüenza evoca la ira contra el otro y, normalmente, esta ira expresada hace que nos avergoncemos de nuevo. Se inicia así una espiral sin fin, como la detectada en las interminables discusiones de pareja. En estos casos, los cónyuges vuelven una y otra vez, compulsivamente, sobre determinados temas conflictivos que acaban sin remedio en abierta discusión, y que nunca resuelven el conflicto. No lo resuelven, en opinión de Scheff, porque bajo el tema que se discute, en realidad un objeto exterior a la relación que está en juego, circula un flujo emocional de vergüenza no reconocida; porque la pareja no discute directamente acerca de su vínculo social, dañado, sino que exporta el problema hacia un objeto exterior a la propia relación. Esto explica que sean conflictos interminables.

Estos conflictos, que acontecen en el seno de la familia, pero también entre las naciones, presentan dos fases asociadas respectivamente a las dos formas de alienación ya descritas. Unas son de discusión abierta, de guerra franca, y se corresponde con el aislamiento, con la excesiva distancia social respecto del otro. Las otras son denominadas por Scheff "impasses de silencio» (silent impasses), y son aquéllas en las que el tema conflictivo es eludido, se rehuye el enfrentamiento directo, y se produce una retirada del yo, una especie de negación del yo en forma de ensimismamiento. Los impasses de silencio no son la paz, sino treguas de conflicto no resuelto entre fases de lucha abierta y frontal. Una sintomática ruptura comunicativa que se corresponde con la forma alienada de la absorción. La vergüenza no reconocida, negada o repri mida, es la que puede llevar al conflicto ${ }^{35}$, sea en el seno de una pareja, sea en el seno de una familia de naciones, como sucedió en Europa en las dos gue-

34. En las situaciones evocadoras de vergüenza, a diferencia de las que evocan culpa, la persona no hace daño al otro desde una posición de control, de poder y de voluntad, lo que exigiría una restitución, sino desde una posición de debilidad y falta de control, de inncopentencia o de incapacidad de la persona para cumplir ciertos requerimientos sociales. Por esto, cuando tropezamos en la calle y hacemos caer a otra persona, se nos trata de tontos, pero no de malvados, y el enfado desaparece con una auténtica solicitud de perdón. Basta, por tanto, que restauremos comunicativamente el vínculo con el otro, que reconozcamos nuestra vergüenza. Éste es el mecanismo subyacente a una teoría del control social orientada al orden.

35. Existen, siguiendo los análisis de Helen B. Lewis, dos tipos de negación de la vergüenza. La vergüenza indefinida o indiferenciada (overt shame), y la vergüenza diferida o evitada (bypassed shame). En la primera el sujeto es consciente de estar experimentando una emoción, pero etiqueta su experiencia con términos ambiguos, indefinidos o indeterminados, es decir, mediante una atribución abierta. En la segunda, el sujeto reconoce cognitivamente la situación, pero no experimenta la vergüenza en tanto emoción. 
rras mundiales de este siglo. En el análisis de Scheff del contexto emocional de ambas guerras, los motivos económicos o de intereses aducidos por diversos tratadistas apenas logran encubrir las sendas humillaciones que dieron lugar a las subsecuentes venganzas de sangre. En el primer caso, «La furia de humillación de los franceses para con los germanos tras la derrota francesa en 1871 fue el principal móvil en la parte de responsabilidad francesa que hizo estallar la Primera Guerra Mundial»(Scheff, 1994: 77). En el segundo, «El ascenso del Hitler al poder fue producido por las calificaciones, por la segregación y por la estigmatización de Alemania tras su derrota en la Primera Guerra Mundial» (Scheff, 1994: 105). En suma, "La Segunda Guerra Mundial fue el resultado del Tratado de Versalles, al igual que la Primera Guerra Mundial fue el resultado del Tratado de Frankfort de 1871» (Scheff, 1994: 121). Dos humillaciones apenas reconocidas.

Pero este resultado no es causa directa de uno u otro de los implicados, tal y como presuponen, buscan y encuentran algunas teorías, sino de las características relacionales del conjunto. Todos los implicados son prisioneros de una peculiar red o estructura de relaciones a la que Scheff denomina "alienación bimodal», concepto con el que podrá darse fin a la exposición de la teoría sociológica de la vergüenza en tanto teoría del conflicto social. La alienación bimodal es muy importante, porque muestra la aplicación de esta teoría al conflicto entre grupos. Expresado con brevedad, alienación bimodal es una estructura de relaciones intragrupales e intergrupales caracterizadas por las dos formas de alienación. Por un lado, en el interior de cada grupo la distancia social es demasiado corta, existe un fuerte proceso de absorción de todo individuo en el grupo, las lealtades son sagradas (engulfment). Por otro, entre los miembros de los dos grupos no existe apenas vínculo, la distancia social es demasiado grande, existe un casi absoluto aislamiento (isola tion). En el interior de cada grupo la presión social es alta, entre los grupos, apenas inexistente. En ambos casos ruptura en la intercomunicación, esto es, silencio, desconocimiento y lejanía. Silencio porque no hay modo de intercomunicación de los puntos de vista alternativos. Éste es el esquema de relación social típico de una guerra entre naciones; éste es también el modelo que puede reconocerse a primera vista en el fenómeno social del terrorismo. El terror crea la barrera que produce el estado de alienación bimodal entre las partes del conflicto, y para todos los participantes. El terror se vive como horror en un lado, sin atisbos de poder reconocerle asomo de legitimidad. En el otro el terror logra cerrar filas mediante una identidad absorbente que deja poco margen a la elección individual. ¿Qué papel tienen aquí el orgullo y la vergüenza? ¿Cómo restablecer los canales de comunicación en los que se pueda hablar directa y respetuosamente sobre el estado del vínculo social? ¿Cómo reparar los vínculos dañados y generar nuevos vínculos seguros que soporten la constitución de un orden social digno para las personas y para los pueblos? 


\section{Bibliografía}

Bericat Alastuey, E. (1998). La integración de los métodos cuantitativo y cualitati vo en la investigación social. Significado y medida. Barcelona: Ariel.

- (1999). «El contenido emocional de la comunicación en la sociedad del riesgo. Microanálisis del discurso». Revista Española de Investigaciones Sociológicas, 87. Cooley, CH.H. (1902). Human Nature and Social Order. Nueva York: Scribner's. DupuY, J.-P. (1999 [1991]). El pánico. Barcelona: Gedisa.

Elias, N. (1993). El proceso de la civilización. Investigaciones sociogenéticas y psicoge néticas. Madrid: F.C.E.

FINE, G.A. (1981). «Review of a Social Interaction Theory of Emotions by Theodore D. Kemper». Social Forces, 59: 1332-1333.

FrANKS, D.D. (1989): "Power and role-taking: a social behaviorist's synthesis of Kemper's power and satus model». En FranKS, D.D.; MCCARTHY, E.D. (ed.). The Sociology of Emotions: Original Essays and Research Papers, Greenwich: Jai Press Inc., p. 153-178.

FuREDI, F. (1997). Culture of Fear. Risk-taking and the morality of low expectation. Londres: Cassel.

GINER, S.; TÁBARA, D. (1998). «Piedad cósmica y racionalidad ecológica». Revista Internacional de Sociología (RIS), tercera época, 19 y 20: 41-67.

Goffman, E. (1956). «Embarrasment and Social Organization». The American Jour nal of Sociology, 62: 264-271.

- (1981 [1959]). La presentación de la persona en la vida cotidiana. Buenos Aires: Amorrortu.

- (1970 [1967]). "La naturaleza de la deferencia y el proceder». En GOFFMAN, E. Ritual de la interacción. Buenos Aires: Tiempo Contemporáneo, p. 48-90.

Gordon, S.L. (1981). "The Sociology of Sentiments and Emotions». En RosenBerg, M.; Turner, R.H.. Social Psychology. Sociological Perspectives. Nueva York: Basic Books, Inc., Publishers.

- (1985). "Micro-sociological theories of emotion». En HELlE, H.J.; EISENSTADT, S.N. (ed.). Micro Sociological Theory, vol. 2 de Perspectives on Socilogical Theory. Londres: Sage.

HeISE, D.R. (1979). Understanding Events: Affect control and the Construction of Social Actions. Cambridge: Cambridge University Press.

Hirschman, A.O. (1999 [1977]). Las pasiones y los intereses. Barcelona: Península. Hochschild, A.R. (1975). "The Sociology of Feeling and Emotion: Selected Possibilities». En Millman, M.; Kanter, R.M. (ed.). Another Voice. Feminist pers pectives on social Life and Social Science. Nueva York: Anchor Books, cap. 10, p. 280-307.

- (1979). «Emotion Work, Feeling Rules and Social Structure». American Journal of Sociology, 85: 551-575.

- (1981). "Power, Status and Emotion». Contemporary Sociology, 10: 73-77.

- (1983). The Managed Heart. Commercialization of Human Feeling. Berkeley: University of California Press.

- (1989a). "The Economy of Gratitude». En FranKS, D.D.; MCCARTHY, E.D. (ed.). The Sociology of Emotions: original Essays and Research Papers. Greenwich: Jai press Inc., p. 95-113. 
- (1989b). The Second Schift. Nueva York: Avon.

- (1990). "Ideology and Emotion Management: A Perspective and Path for Future Research». En Kemper, Th.D. (ed.). Research Agendas in the Sociology of Emo tions. Albany: State University of New York.

- (1997). The Time Bind. When work becomes homes and home becomes work. Nueva York: Metropolitan Books.

KemPER, TH.D. (1978a). «Toward a Sociology of Emotions: some Problems and some Solutions». The American Sociologist, 13: 30-41.

- (1978b). A Social Interactional Theory of Emotions. Nueva York: John Willey \& Sons.

- (1981). «Social Constructionist and Positivist Approaches to the Sociology of Emotions». American Journal of Sociology, 87 (2): 336-362.

- (1987). «How Many Emotions Are There? Wedding the Social and the Autonomic Components». American Journal of Sociology, 93 (2): 263-289.

- (1989). "Love and like and love and love». En FranKs, D.D; Doyle MCCARTHY, E. (ed.). The Sociology of Emotions: Original Essays and Research Papers. Greenwich: Jai Press Inc., p. 249-270.

- (1990a). "Themes and Variations in the Sociology of Emotions». En KEMPER, TH.D. (ed.). Research Agendas in the Sociology of Emotions. Nueva York: State University of New York Press.

- (1990b). «Social Relations and Emotions: A Structural Approach». En KeMPER, TH.D. (ed.). Research Agendas in the Sociology of Emotions. Nueva York: State University of New York Press.

LEWIS, H.B. (1958). "Over-differentiation and Under-differentiation of the Self». Psy choanalysis and the Psychoanalytic Review, 45 (3): 3-24.

- (1971). Shame and Guilt in Neurosis. Nueva York: International University Press.

- (1981). «Shame and Guilt in Human Nature». En TutTMAN, S.; KaYE, C.; ZIMMERMAn, M. Object and Self: A Developmental Approach. Nueva York: International Universities Press, Inc., p. 235-265.

MaCKInNon, N.J. (1994). Symbolic Interactionism as Affect Control. Nueva York: State University of New York Press.

RetZinger, S.M. (1991). Violent Emotions. Shame and Rage in Marital Quarrels. Newbury Park: Sage.

- (1995). «Identifying Shame and Anger in Discourse». American Behavioral Scien tist, 38 (8): 1104-1113

SCHEFF, Th.J. (1966). Being Mentally Ill. Chicago: Aldine.

- (1977). "The Distancing of Emotion in Ritual». Current Anthropology, 18 (3): 483-490.

- (1979). Catharsis in Healing, Ritual and Drama. Berkeley: University of California Press.

- (1983). «Toward Integration in the Social Psychology of Emotions». Annual Review of Sociology, 9: 333-354.

- (1988). «Shame and Conformity: The Deference-Emotion System». American Sociological Review, 53: 395-406.

- (1990a). Microsociology. Discourse, Emotion, and Social Structure. Chicago: The University of Chicago Press. 
- (1990b). «Socialization of Emotions. Pride and Shame as Causal Agents». En Kemper, Th.D. (ed.) Research Agendas in the Sociology of Emotions. Albany: State University of New York.

- (1994). Bloody Revenge. Emotions, Nationalism and War. San Francisco: Westview Press.

- (1995). «Shame and Related Emotions: An Overview» (editor's introduction). American Behavioral Scientist, 38, (8), monográfico dedicado a «Shame and Related Emotions: An Interdisplinary Approach», editado por Th.J. Scheff, p. 10531059.

- (1997). Emotions, the social bond, and human reality. Cambridge: Cambridge University Press.

- (1998). "Three Pioneers in the Sociology of Emotion» (mimeografiado). Universidad de California.

SCHEFF, Th.J.; ReTZINGeR, S.M. (1991). Emotions and violence: Shame and Rage in Destructive Conflicts, Lexington, Lexington Books.

SEnnetT, R.; CobB, J. (1972). The Hidden Injuries of Class. Nueva York: W.W. Norton \& Company.

ShibUTANI, T. (1966). Improvised News. A sociological study of rumor. Indianapolis: The Bobbs-Merrill.

Sнотт, S. (1979). «Emotion and Social Life: A Symbolic Interactionist Analysis». American Journal of Sociology, 84 (6): 1317-1334.

Smith-Lovin, L.; HeISE, D.R. (ed.) (1988). Analyzing Social Interaction: Advances in Affect Control Theory. Nueva York: Gordon \& Breach.

SyKES, G.; MATZA, D. (1957). "Techniques of neutralization: a theory of delinquency». American Sociological Review, 22 (6).

THOITS, P.A. (1985). «Self-labeling Processes in Mental Illness: the Role of Emotional Deviance». American Journal of Sociology, 91 (2), p. 221-249.

- (1989). "The Sociology of Emotions». Annual Review of Sociology, 15: 317-342.

Torregrosa Peris, J.R. (1982). «Emociones, Sentimientos y Estructura Social». En Torregrosa, J.R.; Crespo, E. (ed.). Estudios básicos en Psicología Social. Madrid: Hora/CIS, p. 185-199.

Weber, M. (1979 [1922]). Economía y Sociedad. México: Fondo de Cultura Económica.

- (1998 [1920]). Ensayos sobre sociología de la religión, vol. I. Madrid: Taurus.

Willard Gaylin, M.D. (1984). The Rage Within. Anger in Modern Life. Nueva York: Penguin Book. 